\title{
Breakthrough Infections with Multiple Lineages of SARS-CoV-2 Variants Reveals Continued Risk of Severe Disease in Immunosuppressed Patients
}

\author{
Xufang Deng ${ }^{1}{ }^{\mathbb{D}}$, Monika Evdokimova ${ }^{1}$, Amornrat $\mathrm{O}^{\prime}$ Brien ${ }^{1}$, Cynthia L. Rowe ${ }^{1}$, Nina M. Clark ${ }^{2,3}$, \\ Amanda Harrington ${ }^{3,4}$, Gail E. Reid ${ }^{2,3}$, Susan L. Uprichard ${ }^{1,2,3}$ and Susan C. Baker ${ }^{1,3, *}$ \\ 1 Department of Microbiology and Immunology, Stritch School of Medicine, Loyola University Chicago, \\ Chicago, IL 60153, USA; xufang.deng@okstate.edu (X.D.); mevdokimova@luc.edu (M.E.); \\ aobrien6@luc.edu (A.O.); cynthiarowe@comcast.net (C.L.R.); suprichard@luc.edu (S.L.U.) \\ 2 Department of Medicine, Stritch School of Medicine, Loyola University Chicago, Chicago, IL 60153, USA; \\ NMCLARK@lumc.edu (N.M.C.); greid@lumc.edu (G.E.R.) \\ 3 Infectious Disease and Immunology Research Institute, Stritch School of Medicine, \\ Loyola University Chicago, Chicago, IL 60153, USA; Amanda.Harrington@lumc.edu \\ 4 Department of Pathology and Laboratory Medicine, Stritch School of Medicine, Loyola University Chicago, \\ Chicago, IL 60153, USA \\ * Correspondence: sbaker1@luc.edu
}

\section{check for} updates

Citation: Deng, X.; Evdokimova, M.; O'Brien, A.; Rowe, C.L.; Clark, N.M.;

Harrington, A.; Reid, G.E.;

Uprichard, S.L.; Baker, S.C.

Breakthrough Infections with

Multiple Lineages of SARS-CoV-2

Variants Reveals Continued Risk of

Severe Disease in Immunosuppressed

Patients. Viruses 2021, 13, 1743.

https://doi.org/10.3390/v13091743

Academic Editor: Caijun Sun

Received: 29 July 2021

Accepted: 28 August 2021

Published: 1 September 2021

Publisher's Note: MDPI stays neutral with regard to jurisdictional claims in published maps and institutional affiliations.

Copyright: (c) 2021 by the authors. Licensee MDPI, Basel, Switzerland. This article is an open access article distributed under the terms and conditions of the Creative Commons Attribution (CC BY) license (https:// creativecommons.org/licenses/by/ $4.0 /)$.
Abstract: The pandemic of COVID-19 caused by SARS-CoV-2 infection continues to spread around the world. Vaccines that elicit protective immunity have reduced infection and mortality, however new viral variants are arising that may evade vaccine-induced immunity or cause disease in individuals who are unable to develop robust vaccine-induced responses. Investigating the role of viral variants in causing severe disease, evading vaccine-elicited immunity, and infecting vulnerable individuals is important for developing strategies to control the pandemic. Here, we report fourteen breakthrough infections of SARS-CoV-2 in vaccinated individuals with symptoms ranging from asymptomatic/mild (6/14) to severe disease (8/14). High viral loads with a median $C t$ value of 19.6 were detected in the nasopharyngeal specimens from subjects regardless of disease severity. Sequence analysis revealed four distinct virus lineages, including alpha and gamma variants of concern. Immunosuppressed individuals were more likely to be hospitalized after infection $(p=0.047)$, however no specific variant was associated with severe disease. Our results highlight the high viral load that can occur in asymptomatic breakthrough infections and the vulnerability of immunosuppressed individuals to post-vaccination infections by diverse variants of SARS-CoV-2.

Keywords: SARS-CoV-2; variants of concern; breakthrough infections; post-vaccination infections; COVID-19; immunosuppression

\section{Introduction}

COVID-19 vaccine deployment has dramatically reduced the number of infections, hospitalizations, and deaths caused by SARS-CoV-2 [1,2]. However, there are reports of SARS-CoV-2 infections in fully vaccinated individuals [3-16]. In the majority of individuals, these infections are presumed to be breakthrough infections associated with SARS-CoV-2 variants that escape vaccine-induced immunity. Indeed, studies have experimentally shown that serum from vaccinated individuals is less efficient in neutralizing viral variants $[17,18]$. On the other hand, post-vaccination infection may occur if vaccineinduced immunity is absent or ineffective, such as in solid organ transplant (SOT) recipients who are receiving immunosuppressive therapy [19-24]. Here we describe the characteristics of fourteen SARS-CoV-2 infections in fully vaccinated individuals at our medical center between 29 March 2021 and 29 April 2021 that represent both of these scenarios. 


\section{Materials and Methods}

\subsection{Specimen Collection and Processing}

Between 29 March 2021 and 29 April 2021 we collected nasopharyngeal swab samples from all vaccinated individuals who tested SARS-CoV-2 positive. The protocol for the collection and banking of de-identified samples and associated clinical data was reviewed by the Loyola University Health Sciences Campus Institutional Review Board (IRB) and deemed exempt in accordance with the Department of Health and Human Services regulations at 45 CFR 46.104(d)(4)(ii-iii)(IRB 214365). The de-identified samples and data were then distributed for research under IRB 214451. The demographic and clinical data from the 14 subjects who tested SARS-CoV-2 positive in this one-month period are shown in Table 1. A five hundred microliter sample from the nasopharyngeal swab specimen was processed for RNA extraction.

\subsection{Detection of Viral RNA and Cycle Threshold (Ct)}

Nasopharyngeal swab specimens were extracted for RNA using MagMAX ${ }^{\mathrm{TM}}$ Viral RNA Isolation Kit (ThermoFisher Scientific, Carlsbad, CA, USA) following the manufacturer's instruction. The isolated RNA was eluted in $50 \mu \mathrm{L}$ nuclease-free water and $5 \mu \mathrm{L}$ was used for TaqPath 1-Step RT-PCR (ThermoFisher Scientific, Carlsbad, CA, USA) to measure the level of viral nucleocapsid gene with primers (N1 Forward: 5'-GACCCCAAAATCAGCGAAAT-3'; N1 Reverse: $5^{\prime}$-TCTGGTTACTGCCAGTTGAATCTG-3') and probe (FAM-ACCCCGCAT /ZEN/ TACGTTTGGTGGACC-3IABkFQ).

\subsection{Sequencing of SARS-CoV-2 Complete Genome}

Complete genome amplification using the ARTIC network V3 multiplex primers was performed followed by next-generation sequencing [25]. Briefly, reverse transcription of RNA samples was completed with LunaScript ${ }^{\mathrm{TM}}$ RT SuperMix Kit (NEB) according to the manufacturer's instructions. Multiplexing PCR amplification of cDNA was performed using Q5 Hot Start High-Fidelity Master mix (NEB) with the ARTIC network V3 multiplex primers. Equal molar weight of DNA products of two multiplexing PCR were pooled and subjected to a high-throughput amplicon sequencing (Genewiz, NJ, USA). Sequencing reads were quality controlled by removing low quality reads $(Q$ score $<20)$ and trimming primer sequences. Trimmed reads were aligned to the SARS-CoV-2 reference genome using a bioinformatic tool, iVar [26]. Consensus sequence was obtained when minimal coverage reached $50(p<0.05)$. Complete genomic sequences were analyzed with the NextClade online software (https: / / clades.nextstrain.org, accessed on 21 July 2021) to assign the clade and call amino acid mutations.

\subsection{Evaluating Antibody Response to SARS-CoV-2 Spike Protein}

Enzyme-linked immunosorbent assay (ELISA) was performed using the spike antigen (hexapro) [27], according to the method described by Stadlbauer et al. [28]. Serial dilutions of patient serum were evaluated to identify the point where absorbance was at least 3-fold over the OD of the control serum, which was designated as the end-point titer.

\subsection{Statistical Analysis}

Binomial logistic regression analyses were performed using the $\mathrm{R}$ program to examine the association between explanatory variables and a response variable (hospitalization). 
Table 1. Demographics of patients, clinical and virological findings.

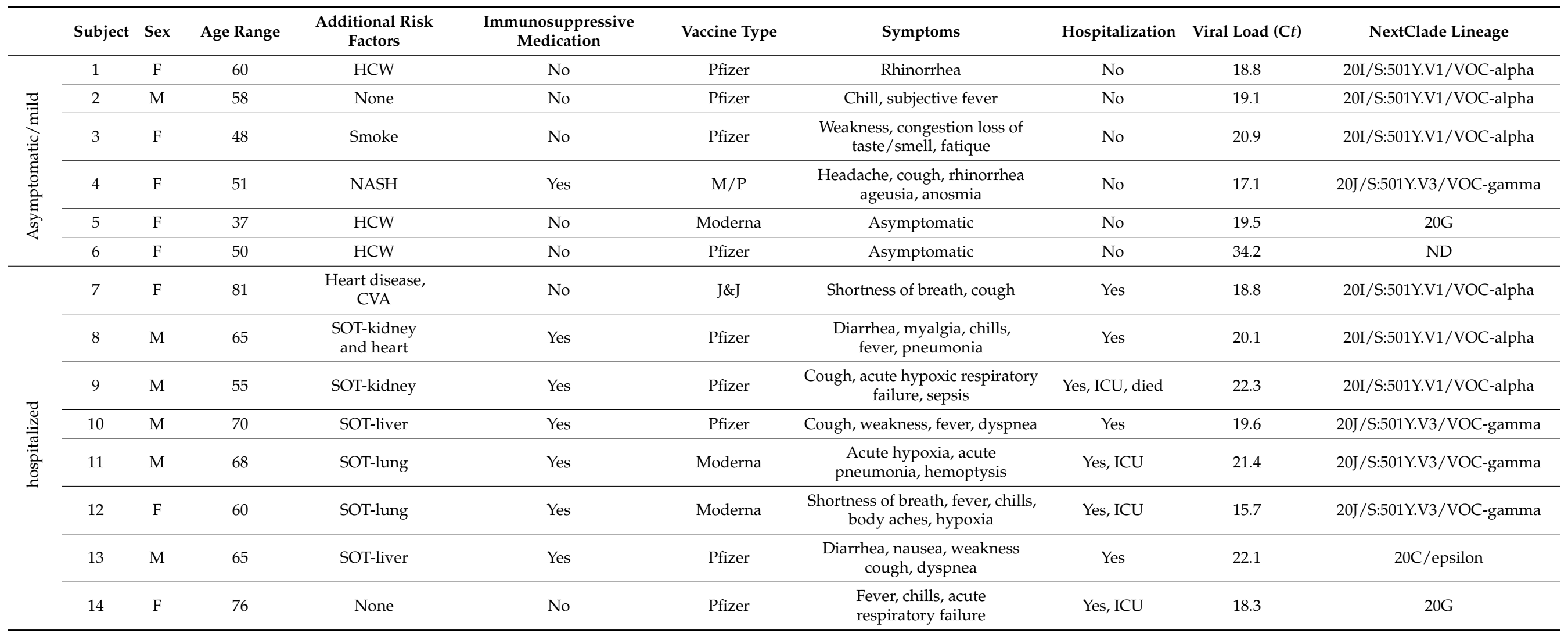

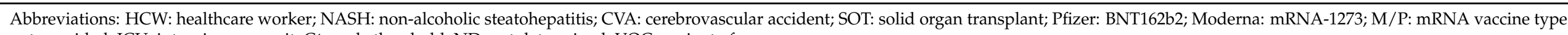
not provided; ICU: intensive care unit; $C t$ : cycle threshold; ND: not determined; VOC: variant of concern. 


\section{Results}

We describe SARS-CoV-2 infections over a 4-week period from 29 March 2021 to 29 April 2021 in fourteen fully vaccinated individuals at Loyola University Medical Center (LUMC) in suburban Chicago, Illinois (Table 1). These breakthrough infections represent $2 \%$ of the 692 positive tests, from a total of 9752 samples evaluated during this time period. The subjects ranged in age from 37 to 81 years old (mean $=60.3$ ) with eight females and six males, 3/14 were healthcare workers and 6/14 were solid organ transplant (SOT) recipients. All subjects had documented records of completing their vaccine regimens at least 14 days prior to testing positive for COVID-19 (range: 14 to 109 days). Three subjects were identified by surveillance or post-exposure testing (S1, S5, and S6) and reported either no symptoms or only rhinorrhea. Serum obtained from Subject 1 at day 2 after testing positive for SARS-CoV-2 revealed a high titer anti-spike antibody response (1:40,000 endpoint titer), which increased by day 24 after infection (1:80,000 endpoint titer), consistent with a boosted anti-spike response after breakthrough infection. Three subjects (S2, S3, and S4) reported symptomatic COVID-19 but did not require hospitalization. Eight subjects (S7-S14) were hospitalized with COVID-19, with four requiring admission to the intensive care unit (ICU). Thirteen subjects recovered from COVID-19; one succumbed to infection. Statistical analysis indicates that being elderly $($ age $>60)(p=0.0202)$ and ongoing treatment with immunosuppressive medication $(p=0.047)$ was significantly associated with severe disease requiring hospitalization after infection. Six of the hospitalized COVID-19 patients were solid organ transplant (SOT) recipients who had completed their vaccine regimens (S8-S13).

To evaluate the viral load in these subjects, RNA was isolated from the nasopharyngeal swabs of all 14 subjects and evaluated for the presence of SARS-CoV-2 RNA using TaqPath 1-step RT-PCR. The cycle threshold $(\mathrm{C} t)$ values ranged from 15.7 to 34.2 (median $=19.6$ ). Only one patient, a healthcare worker without other apparent risks for COVID-19, had a $\mathrm{C} t>30$. There was no association found between disease severity and viral load $(p=0.45)$, with the average $C t$ of the non-hospitalized versus hospitalized group being 19.2 versus 19.6, respectively. These results document the high viral loads present in both symptomatic and asymptomatic patients after breakthrough infections.

To identify the lineage of the SARS-CoV-2 in these patients, we performed the ARTIC multiplexing PCR and high-throughput amplicon sequencing of each sample. Thirteen complete genomes were obtained from the samples with $\mathrm{C} t<30$, with an average coverage above 2000 (2009-3381). Phylogenetic analysis of the complete genomic sequences using the NextClade online software revealed four distinct lineages of SARS-CoV-2 (Figure 1). The majority of the subjects were infected with variants belonging to the Alpha lineage (also known as B.1.1.7) (6/13) or the Gamma lineage (also known as P.1 variant) (4/13), which were the most common variants of concern circulating in the USA in April of 2021 [29] and in Illinois, as documented by sequencing studies performed by the Illinois Department of Public Health (https: / / www.dph.illinois.gov / covid19/variants, accessed on 27 August 2021). Bioinformatic analysis of the deduced amino acid sequence of spike genes revealed eight distinct constellations of mutations in the spike as compared to the reference strain (accession ID: NC_045512.2) (Figure 2). Of the six Alpha lineage variants, four of them have the spike mutations identical to that of the original Alpha strain, while two samples each have an additional spike mutation. Similarly, of the four Gamma lineage samples, three harbored the spike mutations of the original Gamma strain, while one acquired an additional mutation in the cytoplasmic tail domain. We also detected individuals with other lineages: S4 and S6 with the 20G lineage, and S3 with the Epsilon lineage (Epsilon, 20C) that contains the concerning L452R mutation in spike [30]. All spike sequences contained the D614G mutation. The amino acid substitutions in the receptor binding domain (RBD) and N-terminal domain (NTD) have been associated with escape from vaccine-induced neutralizing activity $[30,31]$. We report that no specific variant was associated with more severe disease in healthy individuals or in solid organ transplant patients within this 
cohort. The variants we detected were representative of the viruses circulating in the Chicagoland area in April, 2021 (https:/ / www.dph.illinois.gov/covid19/variants, accessed on 27 August 2021).

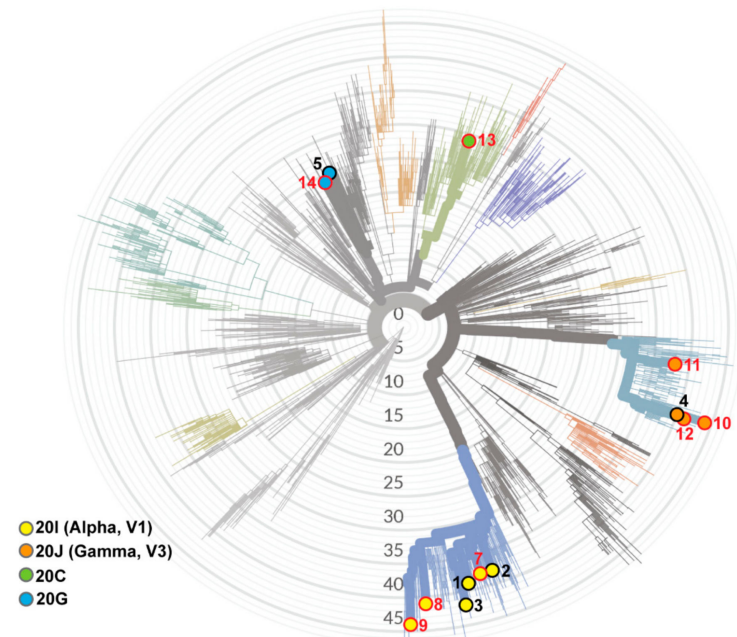

Figure 1. Sequence analyses reveal multiple lineages of SARS-CoV-2 variants associated with breakthrough infections in this study. Phylogenetic tree depicting the lineages of the thirteen SARS-CoV-2 genomic sequences. The complete genome nucleotide sequence obtained from each subject was analyzed with NextClade software (https:/ / clades.nextstrain.org/tree, accessed on 21 July 2021) for clade assignment. WHO designation of variants of concern (VOC) are given in parenthesis. Hospitalized subjects are indicated with a red circle and number; subjects with mild/asymptomatic disease are indicated with a black circle and number.

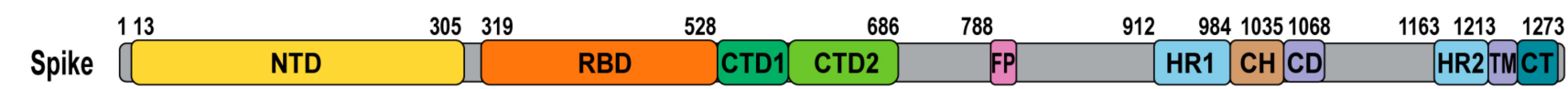

\begin{tabular}{|c|c|c|c|c|c|c|c|c|c|c|c|c|c|c|c|c|c|c|c|c|c|c|c|c|c|c|c|}
\hline Subject \# & $L 5 F$ & S131 & L18F & T20I & P26S & $\mathrm{V}$ & & $138 \mathrm{Y}$ & Y144 & R190S & K417T & L452R & E484K & N501Y & A570D & D614G & H655Y & Q677P & P681H & 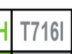 & | E780Q & S982A & L1004S & $T 10271$ & D1118H & V1176F & \begin{tabular}{|l|l|} 
K1191N & M12291 \\
\end{tabular} \\
\hline $1,2,3,7$ & & & & & & & & & & & & & & & & & & & & & & & & & & & \\
\hline 8 & & & & & & & & & & & & & & & & & & & & & & & & & & & \\
\hline 9 & & & & & & & & & & & & & & & & & & & & & & & & & & & \\
\hline $4,10,11$ & & & & & & & & & & & & & & & & & & & & & & & & & & & \\
\hline 12 & & & & & & & & & & & & & & & & & & & & & & & & & & & \\
\hline 13 & & & & & & & & & & & & & & & & & & & & & & & & & & & \\
\hline 5 & & & & & & & & & & & & & & & & & & & & & & & & & & & \\
\hline 14 & & & & & & & & & & & & & & & & & & & & & & & & & & & \\
\hline
\end{tabular}

Figure 2. Multiple mutations in the SARS-CoV-2 spike gene were identified in subjects with breakthrough infections. Schematic diagram of the SARS-CoV-2 spike with functional domains highlighted in color. NTD: N-terminal domain; RBD: receptor-binding domain; CTD1 and CTD2: C-terminal domain 1 and 2; FP: fusion peptide; HR1: heptad repeat 1; $\mathrm{CH}$ : central helix; CD: connector domain; HR2: heptad repeat 2; TM: transmembrane domain; Ct: cytoplasmic tail. The amino acid substitutions deduced from the nucleotide sequence detected in each subject are shown in the boxes and colored according to their location in the spike sequence. Subject numbers in red are the hospitalized cases.

\section{Discussion}

We report that half $(7 / 14)$ of the SARS-CoV-2 breakthrough infections in fully vaccinated people detected at our center over a four-week period occurred in immunosuppressed subjects, with the majority of these immunosuppressed subjects experiencing severe disease requiring hospitalization. Six of the hospitalized patients were SOT recipients, highlighting the vulnerability of these individuals. Combined with recent reports indicating that only a small percentage of transplant patients mount a detectable SARS-CoV-2 
antibody response post vaccination [22,23,32-34], this finding suggests that some immunosuppressed individuals, particularly solid organ transplant recipients, may not generate robust protective responses after vaccination, making them more vulnerable to severe disease if they are infected by a SARS-CoV-2 variant. It remains to be determined whether the higher post-vaccine infection prevalence and associated disease severity observed in immunosuppressed individuals presented here is due to virus exposure in the setting of low or insufficient levels of neutralizing antibody elicited by the vaccine, evasion of vaccine-induced immune response by viral variants, or inadequate cell-mediated immune responses to virus infection. In line with the recommendations in early 2021, none of the immunosuppressed patients in this report were tested for anti-spike antibody response after completion of vaccination. Our current findings raise the question of whether immunosuppressed individuals should be tested for SARS-CoV-2 anti-spike antibody post-vaccination. A recent study indicates that immunization with a third dose of mRNA vaccine boosts the immune response in solid organ transplant recipients [35,36]. More studies are needed to determine the correlates of immunity required to protect from severe COVID-19, and the optimal approaches for eliciting these responses in SOT patients or others undergoing immunosuppressive therapies.

One of the important issues for controlling the spread of variants is to determine if breakthrough infection is associated with high viral loads that may result in secondary spread. Previous studies reported that low viral loads were detected following vaccination $[37,38]$. In contrast, we detected relatively high viral loads (median C $t$ of 19.6) even in nonimmunosuppressed vaccinated subjects exhibiting asymptomatic or mild infection. Among three individuals who were asymptomatic or had mild symptoms, two of them had Ct values of 18.8 and 19.5, respectively, which correlates with high viral loads. Asymptomatic or minimally symptomatic breakthrough infections may occur and go undiagnosed in healthy individuals. In the present study, infections were identified in subjects 1, 5, and 6 solely due to surveillance programs and post-exposure testing, similar to recent reports $[4,13]$. Breakthrough infection in vaccinated asymptomatic subjects, such as those described here, may contribute to the spread of SARS-CoV-2 in the population. Our study is in agreement with several recent reports documenting high viral loads in breakthrough infections in both symptomatic and asymptomatic individuals $[7,12,39]$. More studies are needed to determine the contribution of breakthrough infections in the spread of SARS-CoV-2 variants of concern.

Another finding from this study is that we identified four distinct lineages of SARS-CoV-2 variants (Figure 1). These findings highlight that diverse virus lineages were co-circulating in the Chicago area (https: / / www.dph.illinois.gov/ covid19/variants, accessed on 27 August 2021). The only spike mutation in common for all the variants was the D614G mutation, which arose in early 2020 and rapidly spread, such that this mutation is detected in viruses from around the world [40]. We note that subjects 1, 2, 3, 7, 8, and 9 harbored spike sequences from the Alpha/B.1.1.7 variant of concern lineage. The SARS-CoV-2 Alpha/B.1.1.7 lineage has been shown to be neutralized by convalescent serum from vaccinated individuals [18]. Three out of the six subjects infected with this variant of concern experienced mild disease, with the more severe disease seen in an elderly patient and solid organ transplant patients. The second variant of concern was the Gamma/P.1 lineage in subjects 4, 10, 11, and 12 . This lineage contains the E484K and N501Y mutations that likely contribute to evasion of vaccine-induced immunity and has been associated with re-infection [31,41]. This variant was recently identified by rapid detection in Canada, highlighting the importance of surveillance testing in identifying variants of concern [42]. We also identified a variant containing the L452R mutation (S3) that has been reported to contribute to evasion of vaccine-induced immunity [30]. While this study was in progress, the SARS-CoV-2 Delta variant emerged as the predominant variant spreading in the USA. Recent studies report breakthrough infections and severe disease associated with the Delta variant in transplant recipients $[14,43,44]$. More studies are needed to identify approaches to elicit protective immune responses to emerging variants. 
Our study has limitations. The number of breakthrough infections is small $(n=14)$ over a one-month period at one medical center. The finding that six of the post-vaccination infections were in SOT recipients highlights the vulnerability of this group in our patient population. Our results are in agreement with the recent study of Brosh-Nissimov et al. that reported the characteristics of breakthrough infections in 152 vaccinated individuals identified from January to April 2021. They reported that $40 \%$ of the patients with breakthrough infections were immunocompromised (11\% SOT patients), and that co-morbidities including hypertension and diabetes predisposed to severe COVID-19 [7]. Additional studies are needed to determine if SOT patients are vulnerable to specific variants, and if a subset of variants are associated with more severe disease. Another limitation of our study is that we did not have evidence of an immune response to the vaccine in our vaccinated subjects. Although the vast majority of healthy individuals respond to the vaccines authorized for emergency use, recent studies suggest that SOT patients may require a third immunization to elicit a detectable antibody response to spike protein [35,36]. Future studies will focus on evaluating the antibody response to vaccination in SOT and other immunocompromised patient populations.

Overall, our results highlight the ongoing need for genetic analysis of breakthrough infections, and for developing strategies for reducing the spread of variants and protecting vulnerable populations from severe disease. Recent studies indicate that boosting of vaccinated individuals with vaccines designed to elicit immune responses to SARS-CoV-2 variants enhances neutralizing titers [45]. This approach is likely to reduce breakthrough infections and may lower viral loads in those who do become infected so that secondary spread of infection is also reduced. Importantly, screening for vaccine response in vulnerable populations, such as solid organ transplant recipients, and correlating the response with post-vaccination infections would begin to fill this gap in knowledge.

\section{Conclusions}

We identified SARS-CoV-2 breakthrough infections with variants of concern in vaccinated individuals, with solid organ transplant recipients and other immunosuppressed or elderly individuals at higher risk for severe disease. These results highlight the importance of ongoing monitoring of the spread of SARS-CoV-2 variants and the need for assessing the immune response to vaccination in immunosuppressed individuals.

Author Contributions: Conceptualization, X.D. and S.C.B.; methodology, X.D. and M.E.; software, X.D.; validation, X.D., M.E., A.O. and C.L.R.; formal analysis, X.D., A.O. and C.L.R.; resources, N.M.C., A.H., G.E.R. and S.L.U.; data curation, X.D. and S.L.U.; writing-original draft preparation, X.D. and S.C.B.; writing - review and editing, all authors; visualization, X.D. and A.O.; supervision, S.C.B. and S.L.U.; project administration, S.L.U.; funding acquisition, S.C.B. and S.L.U. All authors have read and agreed to the published version of the manuscript.

Funding: This work was supported by grants (R01AI085089 to SCB) from the National Institutes of Health, and from the Walder Foundation Chicago Coronavirus Assessment Network (C CAN) Initiative.

Institutional Review Board Statement: The protocol for the collection and banking of samples and clinical data was reviewed by the Loyola University Health Sciences Campus Institutional Review Board (IRB) and was deemed exempt in accordance with the Department of Health and Human Services regulations at 45 CFR 46.104(d)(4)(ii-iii) (IRB 214365). The de-identified samples and data were then distributed for research under IRB 214451.

Data Availability Statement: The complete genomic sequences of the thirteen SARS-CoV-2 variants were deposited in the GISAID database with the following accession numbers: EPI_ISL_3048070, EPI_ISL_3048060,EPI_ISL_3048071, EPI_ISL_3048061,EPI_ISL_3048062, EPI_ISL_3048063, EPI_ISL_3048064, EPI_ISL_3048065, EPI_ISL_3048066, EPI_ISL_3048067, EPI_ISL_3048068, EPI_ISL_3048069.

Acknowledgments: We thank the Loyola Clinical Research Office Biorepository for assistance with coordination of this study.

Conflicts of Interest: The authors declare no conflict of interest. 


\section{References}

1. Thompson, M.G.; Burgess, J.L.; Naleway, A.L.; Tyner, H.L.; Yoon, S.K.; Meece, J.; Olsho, L.E.W.; Caban-Martinez, A.J.; Fowlkes, A.; Lutrick, K.; et al. Interim Estimates of Vaccine Effectiveness of BNT162b2 and mRNA-1273 COVID-19 Vaccines in Preventing SARS-CoV-2 Infection Among Health Care Personnel, First Responders, and Other Essential and Frontline Workers-Eight, U.S. Locations, December 2020-March. MMWR Morb. Mortal. Wkly. Rep. 2021, 70, 495-500. [CrossRef]

2. Dagan, N.; Barda, N.; Kepten, E.; Miron, O.; Perchik, S.; Katz, M.A.; Hernán, M.A.; Lipsitch, M.; Reis, B.; Balicer, R.D. BNT162b2 mRNA COVID-19 Vaccine in a Nationwide Mass Vaccination Setting. N. Engl. J. Med. 2021, 384, 1412-1423. [CrossRef]

3. Benenson, S.; Oster, Y.; Cohen, M.J.; Nir-Paz, R. BNT162b2 mRNA COVID-19 Vaccine Effectiveness among Health Care Workers. N. Engl. J. Med. 2021, 384, 1775-1777. [CrossRef]

4. Hacisuleyman, E.; Hale, C.; Saito, Y.; Blachere, N.E.; Bergh, M.; Conlon, E.G.; Schaefer-Babajew, D.J.; DaSilva, J.; Muecksch, F.; Gaebler, C.; et al. Vaccine Breakthrough Infections with SARS-CoV-2 Variants. N. Engl. J. Med. 2021, 384, 2212-2218. [CrossRef]

5. CDC COVID-19 Vaccine Breakthrough Case Investigations Team. COVID-19 Vaccine Breakthrough Infections Reported to CDC_United States, 1 January-30 April 2021. MMWR Morb. Mortal. Wkly. Rep. 2021, 70, 792-793.

6. Philomina, J.B.; Jolly, B.; John, N.; Bhoyar, R.C.; Majeed, N.; Senthivel, V.; Fairoz, C.P.; Rophina, M.; Vasudevan, B.; Imran, M.; et al. Genomic Survey of SARS-CoV-2 Vaccine Breakthrough Infections in Healthcare Workers from Kerala, India. J. Infect. 2021, 83, 237-279. [CrossRef]

7. Brosh-Nissimov, T.; Orenbuch-Harroch, E.; Chowers, M.; Elbaz, M.; Nesher, L.; Stein, M.; Maor, Y.; Cohen, R.; Hussein, K.; Weinberger, M.; et al. BNT162b2 Vaccine Breakthrough: Clinical Characteristics of 152 Fully Vaccinated Hospitalized COVID-19 Patients in Israel. Clin. Microbiol. Infect. 2021. [CrossRef]

8. Health Public Ontario Confirmed Cases of COVID-19 Following Vaccination in Ontario: 14 December 2020 to 7 August 2021. 2021; pp. 1-27. Available online: https:/ / www.publichealthontario.ca/-/media/documents/ncov/epi/covid-19-epi-confirmed-casespost-vaccination.pdf?la=en (accessed on 29 July 2021).

9. $\quad$ Bergwerk, M.; Gonen, T.; Lustig, Y.; Amit, S.; Lipsitch, M.; Cohen, C.; Mandelboim, M.; Gal Levin, E.; Rubin, C.; Indenbaum, V.; et al. COVID-19 Breakthrough Infections in Vaccinated Health Care Workers. N. Engl. J. Med. 2021, NEJMoa2109072. [CrossRef]

10. Duerr, R.; Dimartino, D.; Marier, C.; Zappile, P.; Wang, G.; Lighter, J.; Elbel, B.; Troxel, A.; Heguy, A. Dominance of Alpha and Iota Variants in SARS-CoV-2 Vaccine Breakthrough Infections in New York City. J. Clin. Investig. 2021. [CrossRef]

11. Kustin, T.; Harel, N.; Finkel, U.; Perchik, S.; Harari, S.; Tahor, M.; Caspi, I.; Levy, R.; Leshchinsky, M.; Ken Dror, S.; et al. Evidence for Increased Breakthrough Rates of SARS-CoV-2 Variants of Concern in BNT162b2-mRNA-Vaccinated Individuals. Nat. Med. 2021, 27, 1379-1384. [CrossRef]

12. Brown, C.M.; Vostok, J.; Johnson, H.; Burns, M.; Gharpure, R.; Sami, S. Outbreak of SARS-CoV-2 Infections, Including COVID-19 Vaccine Breakthrough Infections, Associated with Large Public Gatherings-Barnstable County, Massachusetts, July 2021. MMWR Morb. Mortal. Wkly. Rep. 2021, 70, 1059-1062. [CrossRef]

13. Jacobson, K.B.; Pinsky, B.A.; Montez Rath, M.E.; Wang, H.; Miller, J.A.; Skhiri, M.; Shepard, J.; Mathew, R.; Lee, G.; Bohman, B.; et al. Post-Vaccination Severe Acute Respiratory Syndrome Coronavirus 2 (SARS-CoV-2) Infections and Incidence of the Presumptive, B.1.427/B.1.429 Variant Among Healthcare Personnel at a Northern California Academic Medical Center. Clin. Infect. Dis. 2021, 2, 1-8. [CrossRef]

14. Olsen, R.J.; Christensen, P.A.; Long, S.W.; Subedi, S.; Hodjat, P.; Olson, R.; Nguyen, M.; Davis, J.J.; Yerramilli, P.; Saavedra, M.O.; et al. Trajectory of Growth of Severe Acute Respiratory (SARS-CoV-2) Syndrome Coronavirus 2 Variants in Houston, Texas, January through May 2021, Based on 12,476 Genome Sequences. Am. J. Pathol. 2021, 1-19. [CrossRef]

15. Keehner, J.; Horton, L.E.; Pfeffer, M.A.; Longhurst, C.A.; Schooley, R.T.; Currier, J.S.; Abeles, S.R.; Torriani, F.J. SARS-CoV-2 Infection after Vaccination in Health Care Workers in California. N. Engl. J. Med. 2021, 384, 1774-1775. [CrossRef]

16. Cavanaugh, A.M.; Fortier, S.; Lewis, P.; Arora, V.; Johnson, M.; George, K.; Tobias, J.; Lunn, S.; Miller, T.; Thoroughman, D.; et al. COVID-19 Outbreak Associated with a SARS-CoV-2 R.1 Lineage Variant in a Skilled Nursing Facility After Vaccination Program-Kentucky, March 2021. MMWR. Morb. Mortal. Wkly. Rep. 2021, 70, 639-643. [CrossRef]

17. Shen, X.; Tang, H.; McDanal, C.; Wagh, K.; Fischer, W.; Theiler, J.; Yoon, H.; Li, D.; Haynes, B.F.; Sanders, K.O.; et al. SARS-CoV-2 Variant, B.1.1.7 Is Susceptible to Neutralizing Antibodies Elicited by Ancestral Spike Vaccines. Cell Host Microbe 2021, 29, 529-539.e3. [CrossRef]

18. Collier, D.A.; de Marco, A.; Ferreira, I.A.T.M.; Meng, B.; Datir, R.P.; Walls, A.C.; Kemp, S.A.; Bassi, J.; Pinto, D.; Silacci-Fregni, C.; et al Sensitivity of SARS-CoV-2 B.1.1.7 to mRNA Vaccine-Elicited Antibodies. Nature 2021, 593, 136-141. [CrossRef]

19. Peled, Y.; Ram, E.; Lavee, J.; Sternik, L.; Segev, A.; Wieder-Finesod, A.; Mandelboim, M.; Indenbaum, V.; Levy, I.; Raanani, E.; et al. BNT162b2 Vaccination in Heart Transplant Recipients: Clinical Experience and Antibody Response. J. Heart Lung Transplant. 2021. [CrossRef]

20. Marinaki, S.; Adamopoulos, S.; Degiannis, D.; Roussos, S.; Pavlopoulou, I.D.; Hatzakis, A.; Boletis, I.N. Immunogenicity of SARS-CoV-2 BNT162b2 Vaccine in Solid Organ Transplant Recipients. Am. J. Transplant. 2021. [CrossRef]

21. Grupper, A.; Rabinowich, L.; Schwartz, D.; Schwartz, I.F.; Ben-Yehoyada, M.; Shashar, M.; Katchman, E.; Halperin, T.; Turner, D.; Goykhman, Y.; et al. Reduced Humoral Response to mRNA SARS-CoV-2 BNT162b2 Vaccine in Kidney Transplant Recipients without Prior Exposure to the Virus. Am. J. Transplant. 2021, 21, 2719-2726. [CrossRef] 
22. Rincon-Arevalo, H.; Choi, M.; Stefanski, A.L.; Halleck, F.; Weber, U.; Szelinski, F.; Jahrsdörfer, B.; Schrezenmeier, H.; Ludwig, C.; Sattler, A.; et al. Impaired Humoral Immunity to SARS-CoV-2 BNT162b2 Vaccine in Kidney Transplant Recipients and Dialysis Patients. Sci. Immunol. 2021, 6, eabj1031. [CrossRef]

23. Boyarsky, B.J.; Werbel, W.A.; Avery, R.K.; Tobian, A.A.R.; Massie, A.B.; Segev, D.L.; Garonzik-Wang, J.M. Antibody Response to 2-Dose Sars-Cov-2 mRNA Vaccine Series in Solid Organ Transplant Recipients. JAMA J. Am. Med. Assoc. 2021, 325, 2204-2206. [CrossRef]

24. Miele, M.; Busà, R.; Russelli, G.; Sorrentino, M.C.; di Bella, M.; Timoneri, F.; Mularoni, A.; Panarello, G.; Vitulo, P.; Conaldi, P.G.; et al . Impaired Anti-SARS-CoV-2 Humoral and Cellular Immune Response Induced by Pfizer-BioNTech BNT162b2 mRNA Vaccine in Solid Organ Transplanted Patients. Am. J. Transplant. 2021, 21, 2919-2921. [CrossRef]

25. Tyson, J.R.; James, P.; Stoddart, D.; Sparks, N.; Wickenhagen, A.; Hall, G.; Choi, J.H.; Lapointe, H.; Kamelian, K.; Smith, A.D.; et al. Improvements to the ARTIC Multiplex PCR Method for SARS-CoV-2 Genome Sequencing Using Nanopore. Biorxiv Prepr. Serv. Biol. 2020. [CrossRef]

26. Grubaugh, N.D.; Gangavarapu, K.; Quick, J.; Matteson, N.L.; De Jesus, J.G.; Main, B.J.; Tan, A.L.; Paul, L.M.; Brackney, D.E.; Grewal, S.; et al. An Amplicon-Based Sequencing Framework for Accurately Measuring Intrahost Virus Diversity Using PrimalSeq and IVar. Genome Biol. 2019, 20, 8. [CrossRef]

27. Hsieh, C.L.; Goldsmith, J.A.; Schaub, J.M.; DiVenere, A.M.; Kuo, H.C.; Javanmardi, K.; Le, K.C.; Wrapp, D.; Lee, A.G.; Liu, Y.; et al. Structure-Based Design of Prefusion-Stabilized SARS-CoV-2 Spikes. Science 2020, 369, 1501-1505. [CrossRef] [PubMed]

28. Stadlbauer, D.; Amanat, F.; Chromikova, V.; Jiang, K.; Strohmeier, S.; Arunkumar, G.A.; Tan, J.; Bhavsar, D.; Capuano, C.; Kirkpatrick, E.; et al. SARS-CoV-2 Seroconversion in Humans: A Detailed Protocol for a Serological Assay, Antigen Production, and Test Setup. Curr. Protoc. Microbiol. 2020, 57, e100. [CrossRef] [PubMed]

29. USA-CDC. CDC COVID Data Tracker. Available online: https://covid.cdc.gov/covid-data-tracker/\#variant-proportions (accessed on 25 May 2021).

30. Deng, X.; Garcia-Knight, M.A.; Khalid, M.M.; Servellita, V.; Wang, C.; Morris, M.K.; Sotomayor-González, A.; Glasner, D.R.; Reyes, K.R.; Gliwa, A.S.; et al. Transmission, Infectivity, and Antibody Neutralization of an Emerging SARS-CoV-2 Variant in California Carrying a L452R Spike Protein Mutation. Medrxiv Prepr. Serv. Health Sci. 2021. [CrossRef]

31. Li, Q.; Wu, J.; Nie, J.; Zhang, L.; Hao, H.; Liu, S.; Zhao, C.; Zhang, Q.; Liu, H.; Nie, L.; et al. The Impact of Mutations in SARS-CoV-2 Spike on Viral Infectivity and Antigenicity. Cell 2020, 182, 1284-1294.e9. [CrossRef]

32. Song, C.C.; Christensen, J.; Kumar, D.; Vissichelli, N.; Morales, M.; Gupta, G. Early Experience with SARs-CoV-2 mRNA Vaccine Breakthrough Among Kidney Transplant Recipients. Transpl. Infect. Dis. 2021, e13654. [CrossRef]

33. Wadei, H.M.; Gonwa, T.A.; Leoni, J.C.; Shah, S.Z.; Aslam, N.; Speicher, L.L. COVID-19 Infection in Solid Organ Transplant Recipients after SARS-CoV-2 Vaccination. Am. J. Transplant. 2021. [CrossRef] [PubMed]

34. Qin, C.X.; Moore, L.W.; Anjan, S.; Rahamimov, R.; Sifri, C.D.; Ali, N.M.; Morales, M.K.; Tsapepas, D.S.; Basic-Jukic, N.; Miller, R.A.; et al. Risk of Breakthrough SARS-CoV-2 Infections in Adult Transplant Recipients. Transplantation 2021, 1-9. [CrossRef]

35. Kamar, N.; Abravanel, F.; Marion, O.; Couat, C.; Izopet, J.; del Bello, A. Three Doses of an mRNA COVID-19 Vaccine in Solid-Organ Transplant Recipients. N. Engl. J. Med. 2021, 385, 661-662. [CrossRef]

36. Hall, V.; Ferreira, V.; Ku, T.; Ierullo, M.; Majchrzak-Kita, B.; Chaparro, C.; Selzner, N.; Schiff, J.; McDonald, M.; Tomlinson, G.; et al. Randomized Trial of a Third Dose of mRNA-1273 Vaccine in Transplant Recipients. N. Engl. J. Med. 2021. [CrossRef]

37. Teran, R.A.; Walblay, K.A.; Shane, E.L.; Xydis, S.; Gretsch, S.; Gagner, A.; Samala, U.; Choi, H.; Zelinski, C.; Black, S.R. Postvaccination SARS-CoV-2 Infections Among Skilled Nursing Facility Residents and Staff Members-Chicago, Illinois, December 2020-March 2021. MMWR Morb. Mortal. Wkly. Rep. 2021, 70, 632-638. [CrossRef]

38. Levine-Tiefenbrun, M.; Yelin, I.; Katz, R.; Herzel, E.; Golan, Z.; Schreiber, L.; Wolf, T.; Nadler, V.; Ben-Tov, A.; Kuint, J.; et al. Initial Report of Decreased SARS-CoV-2 Viral Load after Inoculation with the BNT162b2 Vaccine. Nat. Med. 2021, 27, 790-792. [CrossRef]

39. Lange, B.; Gerigk, M.; Tenenbaum, T. Breakthrough Infections in BNT162b2-Vaccinated Health Care Workers. N. Engl. J. Med. 2021. [CrossRef]

40. Plante, J.A.; Liu, Y.; Liu, J.; Xia, H.; Johnson, B.A.; Lokugamage, K.G.; Zhang, X.; Muruato, A.E.; Zou, J.; Fontes-Garfias, C.R.; et al. Spike Mutation D614G Alters SARS-CoV-2 Fitness. Nature 2021, 592, 116-121. [CrossRef]

41. Resende, P.C.; Bezerra, J.F.; Vasconcelos, R.H.T.; Arantes, I.; Appolinario, L.; Mendonca, A.C.; Paixao, A.C.; Duarte, A.C.; Silva, T.; Rocha, A.S.; et al. Severe Acute Respiratory Syndrome Coronavirus 2 P.2 Lineage Associated with Reinfection Case, Brazil, June-October 2020. Emerg. Infect. Dis. 2021, 27, 1789-1794. [CrossRef]

42. Matic, N.; Lowe, C.F.; Ritchie, G.; Stefanovic, A.; Lawson, T.; Jang, W.; Young, M.; Dong, W.; Brumme, Z.L.; Brumme, C.J.; et al. Rapid Detection of SARS-CoV-2 Variants of Concern, Including, B.1.1.28/P.1, British Columbia, Canada. Emerg. Infect. Dis. 2021, 27, 1673-1676. [CrossRef]

43. Connor, B.A.; Couto-Rodriguez, M.; Barrows, J.E.; Gardner, M.; Rogova, M.; O'Hara, N.B.; Nagy-Szakal, D. Monoclonal Antibody Therapy in a Vaccine Breakthrough SARS-CoV-2 Hospitalized Delta (B.1.617.2) Variant Case. Int. J. Infect. Dis. 2021. [CrossRef] [PubMed]

44. Farinholt, T.; Doddapaneni, H.; Qin, X.; Menon, V.; Meng, Q.; Metcalf, G.; Chao, H.; Gingras, M.-C.; Farinholt, P.; Agrawal, C.; et al. Transmission Event of SARS-CoV-2 Delta Variant Reveals Multiple Vaccine Breakthrough Infections. Medrxiv Prepr. Serv. Health Sci. 2021. [CrossRef]

45. Wu, K.; Choi, A.; Koch, M.; Ma, L.; Hill, A.; Nunna, N.; Huang, W.; Oestreicher, J.; Colpitts, T.; Bennett, H.; et al. Preliminary Analysis of Safety and Immunogenicity of a SARS-CoV-2 Variant Vaccine Booster. Medrxiv Prepr. Serv. Health Sci. 2021. [CrossRef] 